\title{
A CONCRETIZAÇAO DO DIREITO FUNDAMENTAL AO MEIO AMBIENTE ECOLOGICAMENTE EQUILIBRADO MEDIANTE A EXTRAFISCALIDADE
}

IMPLEMENTATION OF THE FUNDAMENTAL RIGHT TO AN ECOLOGICALLY BALANCED ENVIRONMENT THROUGH EXTRA-TAXATION

LA CONCRECIÓN DEL DERECHO FUNDAMENTAL AL MEDIO AMBIENTE ECOLÓGICAMENTE EQUILIBRADO MEDIANTE LA EXTRAFISCALIDAD

Luciana Turatti ${ }^{1}$

Marciano Buffon²

Ana Christina Konrad 3

1 Doutora em Direito pelo Programa de Pós-Graduação em Direito da UNISC. Lajeado/RS, Brasil. Professora dos cursos de Graduação e Pós-Graduação do Centro Universitário UNIVATES. lucianat@univates.br

2 Doutor em Direito pela Universidade do Vale do Rio dos Sinos - UNISINOS. Novo Hamburgo/RS, Brasil. Professor do Programa de Pós-Graduação em Direito (Mestrado) e da graduação na UNISINOS. Advogado na área tributária. marciano@buffonefurlan.com.br

3 Mestranda em Ciências Ambientais pelo Programa de Pós-Graduação Ambiente e Desenvolvimento da UNIVATES. Arroio do Meio/RS, Brasil. Bolsista PROSUP/CAPES. anamajolo@ universo.univates.br 
Resumo: O presente trabalho analisa as possibilidades de a tributação ser um eficaz meio de concretização do direito fundamental ao meio ambiente ecologicamente equilibrado, num cenário marcado por formas de desenvolvimento que comprometem o meio ambiente de maneira que são necessárias medidas urgentes a fim de salvaguardar os recursos naturais não renováveis e, por consequência, diversas espécies da fauna e da flora em extinção. $O$ direito ao meio ambiente ecologicamente equilibrado encontrase ligado ao direito à vida, sendo pressuposto deste, e como tal deve ser alvo de proteção do Estado. Para tanto, faz-se necessária uma ação Estatal efetiva - distanciada da neutralidade apregoada pelo modelo liberal individualista - no sentido de, sobretudo, estimular práticas ambientais preventivas e protetivas, mediante a realização de normas tributárias indutoras. O Estado dispõe de poderosos instrumentos para consecução destes propósitos, entre os quais se cita a extrafiscalidade, hipótese na qual o mesmo, via tributação, busca atingir os fins de sua existência - realização de direitos fundamentais e concretização de princípios constitucionais - e não visa apenas à obtenção de receitas derivadas para que, com isso, reste preservado e perseguido o "interesse humano" na tributação. O método empregado na construção do presente artigo foi o dedutivo. Ao final da discussão chega-se à conclusão de que a extrafiscalidade tem um importante papel a desempenhar em um cenário que vise à concretização do direito fundamental ao meio ambiente ecologicamente equilibrado, uma vez que esta é capaz de induzir ou desestimular comportamentos por meio da simples majoração ou diminuição de tributos.

Palavras-chave: extrafiscalidade - meio ambiente - normas indutoras - tributação

Abstract: This paper explores the possibilities of taxation as an effective means of realizing the fundamental right to an ecologically balanced environment, in a scenario marked by forms of development that threaten the environment in such a way that urgent measures are needed to safeguard the exhaustible natural resources and, consequently, several species of wild fauna 
and flora that are in danger of extinction. The right to an ecologically balanced environment is connected to the right to life, as a basic premise, and as such, it should be subject to state protection. Therefore, it is necessary to have an effective State action - distanced from the neutrality proclaimed by the liberal individualist model - in order encourage, above all, preventive and protective environmental practices through the implementation of inducing tax rules. The state has powerful instruments for this purpose, such as the use of extra-taxation, whereby the state, through taxation, strives to achieve the purpose of its existence - the implementation and realization of fundamental constitutional principles - and not only to obtain derived revenues - so that the "human interest" is preserved and pursued through the taxation. The deductive method used in the construction of this article. At the end of the discussion, the authors comes to the conclusion that extra-taxation plays an important role in a scenario aimed at the realization of the fundamental right to an ecologically balanced environment, as it is capable of inducing or discouraging behaviors by simply increasing or decreasing taxes.

Keywords: extra-taxation - environment - inducing rules - taxation

Resumen: El presente trabajo analiza las posibilidades de que la tributación sea un medio eficaz para la concreción del derecho fundamental al medio ambiente ecológicamente equilibrado en un escenario marcado por formas de desarrollo que comprometen el medio ambiente, de manera que se hacen necesarias medidas urgentes a fin de salvaguardar los recursos naturales no renovables, y en consecuencia, diversas especies en extinción de la fauna y de la flora. El derecho al medio ambiente ecológicamente equilibrado se encuentra vinculado al derecho a la vida, y es el presupuesto del mismo, y como tal debe ser objeto de protección del Estado. Para ello se vuelve necesaria una acción estatal efectiva - alejada de la neutralidad pregonada por el modelo liberal individualista - que sobre todo estimule prácticas ambientales preventivas y de protección, mediante la realización de normas tributarias inductoras. El Estado dispone de poderosos instrumentos para el logro de estos 
propósitos, entre los cuales se cita la extrafiscalidad, hipótesis en la cual el mismo, a través de tributación, busca alcanzar los fines de su existencia - realización de derechos fundamentales y concreción de principios constitucionales - y no se propone solamente la obtención de ingresos derivados -, para que con ello quede preservado y perseguido el "interés humano" en la tributación. El método empleado en la construcción del presente artículo fue el deductivo. Al final de la discusión se llega a la conclusión de que la extrafiscalidad juega un importante papel en un escenario cuyo objetivo es la concreción del derecho fundamental al medio ambiente ecológicamente equilibrado, ya que la misma es capaz de inducir o desestimular comportamientos por medio de un sencillo aumento o disminución de tributos.

Palabras clave: Extrafiscalidad; Medio ambiente; Normas inductoras; Tributación

\section{INTRODUÇÃO}

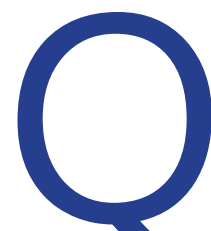

uando se examina a evolução da ideia de Estado, constata-se que este processo se dá de uma forma indissociável à concepção de direitos fundamentais e à tributação. Se ao Estado Liberal clássico bastará assegurar a vida liberdade e propriedade, ao Estado contemporâneo (democrático e social de direito) incumbe a inalienável tarefa de assegurar uma existência minimamente digna a todos e isso passa pela concretização dos direitos fundamentais de todas as dimensões.

Em vista disso, a exigência de tributos há de ser hodiernamente entendida como um dever fundamental de cidadania, uma vez que é por meio desta que o Estado assegura os recursos necessários para garantir a realização de programas e políticas direcionadas na obtenção do denominado "bem comum", razão esta da sua própria existência.

Pode-se dizer que, dentro de uma concepção contemporaneamente adequada de bem comum, a concretização dos direitos fundamentais assegurados 
constitucionalmente ocupa um espaço central, sendo que entre esse desponta com inequívoca importância o direito fundamental ao meio ambiente ecologicamente equilibrado, entendido consensualmente como direito de terceira geração/dimensão.

Há de se reconhecer que este grau de importância decorre justamente pelo fato que o ambiente se encontra em uma situação de risco, em face de escolhas relacionadas a formas de desenvolvimento predatórias utilizadas ao longo do último século. O resultado destas escolhas implica um meio ambiente degradado - com recursos naturais beirando o esgotamento - e depredado, em especial com relação à flora e à fauna.

Tendo em vista tais preocupações, faz-se necessário examinar de que forma a tributação pode servir de instrumento apto a colaborar na difícil tarefa da realização do direito fundamental ao meio ambiente ecologicamente equilibrado.

A ideia a ser defendida diz respeito à possibilidade de o Estado utilizar a tributação como instrumento de intervenção na sociedade e na economia, com o objetivo de concretizar o direito fundamental ao meio ambiente. Por meio da tributação, em sua faceta extrafiscal, pode o Estado estimular ou desestimular comportamentos e condutas.

Assim, serão analisados a seguir, pressupostos, limites e fins possíveis para as políticas extrafiscais, além da possibilidade de instituição de normas indutoras de práticas que busquem a efetivação e operacionalização do direito ao meio ambiente. Eis o intento que aqui se persegue.

\section{O MEIO AMBIENTE COMO DIREITO FUNDAMENTAL}

Tendo em vista que no presente artigo pretende-se discorrer acerca da concretização do direito fundamental ao meio ambiente por meio da tributação, nada mais oportuno do que iniciar esta discussão a partir da compreensão de fundamentalidade de tal direito.

A Conferência das Nações Unidas sobre Meio Ambiente, realizada em Estocolmo em 1972, consagrou em seu Princípio I que:

4 A Conferência de Estocolmo sobre Meio Ambiente de 1972 ficou caracterizada como o 
O homem tem o direito fundamental à liberdade, à igualdade e ao desfrute de condições de vida adequada em um meio, cuja qualidade Ihe permita levar uma vida digna e gozar de bem-estar, e tem a solene obrigação de proteger e melhorar esse meio para as gerações presentes e futuras.

Esse princípio, do ponto de vista internacional, significou o reconhecimento do direito do ser humano a um bem jurídico fundamental: o meio ambiente ecologicamente equilibrado e a dignidade humana. Além disso, firmou um comprometimento de todos a preservar o meio ambiente para as presentes e futuras gerações.

Como resultado desse reconhecimento internacional, o constituinte brasileiro estabeleceu na Constituição Federal de 1988, em seu artigo 225, que "todos têm direito ao meio ambiente ecologicamente equilibrado, bem de uso comum do povo e essencial à sadia qualidade de vida, impondo-se ao Poder Público e à coletividade o dever de defendê-lo e preservá-lo para as presentes e futuras gerações".

Ao declarar que todos têm direito ao meio ambiente sadio e, ao impor posteriormente a incumbência de o Estado e da coletividade de protegê-lo, não há como negar que se trata de um direito fundamental, mesmo não estando inserido no capítulo dos direitos e dos deveres individuais e coletivos. ${ }^{5}$

É neste sentido a afirmação de Canotilho ao referir que o direito ao meio ambiente ecologicamente equilibrado é direito de terceira geração, alicerçado na "fraternidade" ou na "solidariedade". E segue o mesmo mencionando que nessa categoria, tem-se "direitos que não se destinam especificamente à proteção dos primeiro instrumento em matéria de Direito Internacional Ambiental. Em seu texto, preâmbulo e 26 princípios, foram abordadas as principais questões que assolavam o planeta, recomendando critérios para sua salvaguarda.

5 Ao fazer referência aos direitos de terceira geração, em que está incluído o direito ao meio ambiente, Bonavides declara que: "Com efeito, um novo pólo jurídico de alforria do homem se acrescenta historicamente aos da liberdade e da igualdade. Dotados de altíssimo teor de humanismo e universalidade, os direitos de terceira geração tendem a cristalizar-se neste fim de século enquanto direitos que não se destinam especificamente à proteção dos interesses de um indivíduo, de um grupo ou de um determinado Estado. Tem primeiro por destinatário o gênero humano mesmo, num momento expressivo de sua afirmação como valor supremo em termo de existencialidade concreta. Os publicistas e juristas já os enumeram com familiaridade, assinalando-Ihe o caráter fascinante de coroamento de uma evolução de trezentos anos na esteira da concretização dos direitos fundamentais. Emergiram eles da reflexão sobre temas referentes ao desenvolvimento, à paz, ao meio ambiente, à comunicação e ao patrimônio comum da humanidade". BONAVIDES, Paulo. Curso de Direito Constitucional. 12 ed. SP: Malheiros, 2002, p. 523. 
interesses de um indivíduo, de um grupo ou de um determinado Estado. Têm primeiro por destinatário o gênero humano mesmo, num momento expressivo de sua afirmação como valor supremo em termos de exigência concreta. ${ }^{6}$

Daí a associação direta entre o direito ao meio ambiente ecologicamente equilibrado e o direito à vida - motivo que reforça seu caráter de fundamental -, posição compartilhada por Milaré na seguinte passagem:

(...) o reconhecimento do direito a um meio ambiente sadio configurase, na verdade, como extensão do direito à vida, quer sob o enfoque da própria existência física e saúde dos seres humanos, quer quanto ao aspecto da dignidade desta existência - a qualidade de vida -, que faz com que valha a pena viver. Deveras, "o caráter fundamental do direito à vida torna inadequados enfoques restritos do mesmo em nossos dias; sob o direito à vida, em seu sentido próprio e moderno, não só se mantém a proteção contra qualquer privação arbitrária da vida, mas além disso encontram-se os Estados no dever de buscar diretrizes destinadas a assegurar o acesso aos meios de sobrevivência a todos os indivíduos e todos os povos. Neste propósito, têm os Estados a obrigação de evitar riscos ambientais sérios à vida. ${ }^{7}$

Fica evidente assim que o direito a um meio ambiente sadio e ecologicamente equilibrado configura-se como extensão ou corolário do direito à vida, e daí o seu caráter de fundamental.

Reconhecido o caráter de fundamental ao meio ambiente, resta responder a seguinte indagação: como conciliar o ímpeto do sistema capitalista com a preocupação com o meio ambiente em um contexto marcado por formas de desenvolvimento que comprometem o meio ambiente de forma tal que, são necessárias medidas urgentes a fim de salvaguardar os recursos naturais não renováveis e, por consequência, diversas espécies da fauna e da flora em extinção. É fato que o processo de industrialização e o modelo de crescimento ilimitado presente em grande parte dos países, principalmente e após a Revolução Industrial e após a Segunda Guerra Mundial, trouxeram consequências imprevisíveis para a atmosfera, o solo, a água e para todos os seres vivos.

6 LEITE, José Rubens; CANOTILHO, José Joaquim Gomes. Direito Constitucional Ambiental Brasileiro. SP: Saraiva, 2007, p. 103

7 MILARÉ, Édis, Direito do Ambiente. São Paulo: RT, 2000, p. 96. 
A Constituição traz um indicativo de como fazê-lo quando estabelece em seu artigo 170 que o desenvolvimento econômico se encontra condicionado à observância dos princípios ambientais, propondo assim o desenvolvimento sustentável. ${ }^{8}$

E é esta a discussão que o presente artigo pretende alcançar. Mas, para tanto, antes de adentrar nas normas tributárias indutoras de práticas ambientais são necessários alguns esclarecimentos sobre a fiscalidade e a extrafiscalidade, bem como sobre as disposições constitucionais acerca do tema.

\section{CONCEITO DE FISCALIDADE E EXTRAFISCALIDADE E FUNDAMENTO CONSTITUCIONAL DA EXTRAFISCALIDADE}

A fiscalidade e a extrafiscalidade estão ligadas ao valor finalístico que o legislador decidiu atribuir a norma tributária. Assim sendo, a fiscalidade referese à forma como o Estado arrecada tributos com o objetivo de obter recursos necessários à implementação de políticas públicas aptas a concretizar as grandes promessas constitucionais, bem como financiar o custeio do próprio Estado.

Não obstante o exposto, a tributação pode desempenhar um papel interventivo direto nas condutas humanas, sendo que tal função tem sido denominada de extrafiscal. Embora à aplicabilidade de normas extrafiscais também resulte arrecadação de recursos por parte do Estado, este não é seu fim primordial. A extrafiscalidade aparece como mecanismo de intervenção econômica, sendo que nessa linha sustenta Paulo de Barros Carvalho que:

Fala-se em fiscalidade sempre que a organização jurídica do tributo denuncie que os objetivos que presidiram sua instituição, ou que governam certos aspectos da sua estrutura, estejam voltados ao fim

8 Por desenvolvimento sustentável entende-se o desenvolvimento capaz de suprir as necessidades da geração atual, sem comprometer a capacidade de atender às necessidades das futuras gerações. É o desenvolvimento que não esgota os recursos para o futuro. Sobre o princípio do desenvolvimento sustentável referem Marchesan, Steigleder e Capelli que "esse princípio parte do pressuposto de que a sociedade humana não se limita às nossas gerações, sendo que a exauribilidade é uma característica dos recursos naturais. Ele deixa clara a reciprocidade entre o direito ao meio ambiente sadio e o dever de preservá-lo para as presentes e futuras gerações, marcando também a nota da solidariedade característica dos direitos de $3^{a}$ geração." MARCHESAN, Ana Maria Moreira; STEIGLEDER, Annelise Monteiro; CAPPELI, Sílvia. Direito Ambiental. 6. ed. Porto Alegre: Verbo Jurídico, 2010, p. 62 
exclusivo de abastecer os cofres públicos, sem que outros interesses - sociais, políticos ou econômicos - interfiram no direcionamento da atividade impositiva. ${ }^{9}$

Por sua vez, o jurista lusitano, Casalta Nabais, define a extrafiscalidade como:

[...] o conjunto de normas que, embora totalmente o conjunto de normas que, embora formalmente integrem o direito fiscal, tem por finalidade principal ou dominante a consecução de determinados resultados económicos ou sociais através da utilização do instrumento fiscal e não a obtenção de receitas para fazer frente face às despesas públicas. ${ }^{10}$

De forma clara e objetiva, Carrazza expõe que existe extrafiscalidade quando o legislador, em nome do interesse coletivo, aumenta ou diminui as alíquotas e/ou as bases de cálculo dos tributos, como o objetivo principal de induzir os contribuintes a fazer ou deixar de fazer alguma coisa. ${ }^{11}$

O que se percebe a partir destes conceitos é que toda tributação implica intervenção do Estado na economia. A distinção, pois, reside na intensidade da intervenção, bem como na proponderância da finalidade. Quando o objetivo meramente arrecadatário mostra-se mais intenso, está-se diante da fiscalidade; quando o objetivo é estimular/induzir ou desistimular determinados comportamentos, trata-se de prevalência da conotação extrafiscal. De qualquer forma, não se pode dizer que um tributo terá caráter somente fiscal ou extrafiscal. Os objetivos fiscais e extrafiscais coexistem.

De outra baila, pode-se afirmar que, tanto na fiscalidade como na extrafiscalidade busca-se a obtenção do bem comum, haja vista que, se por um lado o e Estado necessita de recursos para fazer frente aos dispêndios necessários na promoção de suas políticas públicas, por outro lado o Estado, mediante a indução ou o desestímulo de condutas, direciona comportamentos que estejam em consonância com seu fim maior.

Definidas as diferenças entre a fiscalidade e a extrafiscalidade e considerando que o objetivo deste artigo é tratar das normas indutoras de práticas ambientais, 9 CARVALHO, Paulo de Barros. In SOUZA, Jorge Henrique de Oliveira Souza. Tributação e meio ambiente. Belo Horizonte: Del Rey, 2009, p. 99

10 CASALTA NABAIS, José. O Dever Fundamental de Pagar Impostos. Coimbra: Almedina, p. 629 11 CARRAZZA, Roque Antonio. In SOUZA, Jorge Henrique de Oliveira Souza. Op. cit., p. 101 
será dado um destaque maior à extrafiscalidade, a partir deste momento, haja vista que esta se aproxima mais dos instrumentos utilizados para estimular ou induzir tais práticas.

\section{O fundamento constitucional}

Da análise precedente decorre que a tributação extrafiscal implica o tratamento diferenciado para aqueles que se encontram em situação de igualdade, haja vista que se pretende por meio desta estimular uma determinada prática ou conduta. À primeira vista, tal afirmação conduziria à afirmação de que a extrafiscalidade fere a constituição, posto que afronta o princípio da igualdade.

Contudo, a partir de uma interpretação hermeneuticamente adequada, temse que a extrafiscalidade possui alicerce constitucional, pois tem como finalidade maior a concretização da própria Constituição.

Não se pode falar, desse modo, que, uma vez observados determinados limites, as discriminações perpetradas pela extrafiscalidade sejam contrárias à constituição por afronta ao princípio da igualdade, tendo em vista que elas devem ter por objetivo efetivar e concretizar aqueles princípios consagrados no próprio texto constitucional. A priori, portanto, a extrafiscalidade se legitima na exata proporção da legitimidade dos objetivos visados e isso se verificará, certamente, quando os fins visados passarem pela realização dos direitos fundamentais. ${ }^{12}$

Com base no exposto fica claro que a tributação extrafiscal é o produto da interpretação constitucional. A exigência tributária poderá ser extrafiscal sem com isso afrontar os princípios constitucionais instituídos, pelo contrário, com a extrafiscalidade pode-se dar maior densificação aos direitos fundamentais mediante a intervenção econômica voltada para redução das desigualdades.

Para isto, é de suma importância que os objetivos a serem alcançados com a extrafiscalidade observem os grandes objetivos visados na Constituição de 1988, ou seja, sua fundamentação deve ser constitucional.

12 BUFFON, Marciano. Tributação e dignidade humana: entre os direitos e deveres fundamentais. Porto Alegre: Livraria do Advogado, 2009, p. 224 
Assim, com base no exposto até o momento, resta claro que a extrafiscalidade pode ser um poderoso instrumento para concretização do direito fundamental ao meio ambiente, haja vista sua estreita ligação com os demais direitos fundamentais. A aplicação deste instrumento pode ocorrer de duas formas: estimulando ou desestimulando comportamentos. Para o estímulo podem ser utilizados os benefícios ou os incentivos fiscais, enquanto que, para o desestímulo, deve-se ampliar a exigência tributária.

Nesta linha, Casalta Nabais apresenta as duas formas de extrafiscalidade:

(...) a extrafiscalidade se expande por dois grandes domínios, cada um deles traduzindo uma técnica de intervenção ou de conformação social por via fiscal: a dos impostos extrafiscais, orientados para a dissuação ou evitação de determinados comportamentos (em que são de integrar os chamados agravamentos extrafiscais de impostos fiscais), e a dos benefícios fiscais dirigidos ao fomento, incentivo ou estímulo de determinados comportamentos. ${ }^{13}$

Há de se reconhecer que o enfoque dos benefícios e dos incentivos fiscais visando estimular comportamentos ambientalmente adequados mostra-se mais eficaz na concretização do objetivo perseguido, motivo pelo qual este trabalho reserva um espaço de central importância àqueles, conforme segue.

\section{EXTRAFISCALIDADE E BENEFÍCIOS FISCAIS}

Daanálise precedenteconstata-sequea extrafiscalidadepodeserimplementada de duas formas. No entanto, a face mais visível e eficaz reside na concessão de benefícios ou incentivos fiscais, operacionalizada mediante isenções parciais ou totais, redução de alíquotas ou concessão de créditos fiscais.

Nesta mesma linha de raciocínio Casalta Nabais sustenta que:

Efectivamente, é no domínio dos chamados benefícios fiscais que a extrafiscalidade se revela em termos mais significativos e freqüentes, pois que é geralmente reconhecido integrar o seu próprio conceito a natureza ou carácter extrafiscal como, de resto, se verifica no conceito legal que a nossa ordem jurídica nos fornece - $\mathrm{o}$ art. $2^{\circ}, \mathrm{n}^{\circ} 1$, do EBF, 
que define os benefícios fiscais como medidas de caráter excepcional instituídas para tutela de interesses públicos extrafiscais relevantes e que sejam superiores aos da própria tributação que impedem". Pelo que os benefícios fiscais são, em si mesmos, medidas extrafiscais, o que os distingue designadamente dos chamados desagravamentos fiscais stricto sensu (não-sujeições tributárias que consubstanciadas em medidas fiscais estruturais de carácter normativo que estabeleçam delimitações negativas expressas da incidência,os quais, muito embora também possam ter por base, como de resto é freqüente, razões de natureza extrafiscal, não integram a verdadeira extrafiscalidade ou extrafiscalidade externa, já que eles sempre se conformam com as normas e princípios especificamente respeitantes à estrutura do imposto cuja incidência visam delimitar negativamente, configurando-se assim como medidas de política fiscal e não medidas de política económica e social por via fiscal, ou seja medidas que embora traduzam despesas fiscais enquanto diminuem as receitas ou a produtividade dos correspondentes impostos, são adoptadas pelo legislador fiscal no exercício do seu poder tributário, isto é, enquanto seleciona e delimita os factos tributários pro-nunciando-se sobre o que pretende tributar e o que não pretende tributar em função da política de impostos adoptada. Em suma, dos benefícios fiscais são de afastar estes desagravamentos que se situam no domínio da chamada erosão fiscal (pela erosão da matéria colectável ou do imposto que provocam) ou da extrafiscalidade interna. ${ }^{14}$

Por óbvio, a concessão de benefícios/incentivos deve estar voltada a concretização dos direitos fundamentais - caso este do direito ao meio ambiente ecologicamente equilibrado -, ao desenvolvimento social e econômico de uma determinada região ou ainda ao incentivo de uma atividade que seja de interesse da coletividade.

Os benefícios fiscais devem ser orientados pelos princípios constitucionais, não pode ficar à mercê de interesses econômicos ou políticos, influenciados por lobbies e interesses particulares. Para se evitar tais influências é necessário que o processo que concede benefícios fiscais seja o mais democrático possível, para que não se recaia em situações contrárias aos objetivos constitucionais.

Assim, a concessão de benefícios e incentivos fiscais conduz a um debate aberto acerca do tipo de Estado que se quer ter, do tamanho deste e dos objetivos propostos, uma vez que, os benefícios fiscais não podem ser compreendidos como "prêmios" concedidos pelo Estado para determinado segmento ou setor. 14 CASALTA NABAIS, José. Op. cit., 2004, p. 630 
Por envolver a transferência de recursos de toda sociedade é de fundamental importância a participação desta no processo de decisão dos beneficiários, e ainda, a observância, aos pressupostos, limites e objetivos constitucionais que condicionam e legitimam a extrafiscalidade.

\section{NORMAS TRIBUTÁRIAS INDUTORAS}

A partir do exposto até o momento, constata-se que a tributação é o instrumento pelo qual o Estado promove a intervenção nas questões econômicas, sociais e culturais, sendo assim um poderoso instrumento para realização dos direitos fundamentais, sem, contudo, se afastar da ideia de segurança jurídica, haja vista que, os tributos extrafiscais, devem se submeter aos princípios constitucionais pertinentes a tributação como a igualdade, a legalidade, a generalidade, entre outros.

Por isso, urge encontrar meios de atuação estatal como a introdução de normas indutoras de políticas tributárias, que tenham como objetivo a máxima eficácia dos direitos fundamentais, em especial daqueles ligados a temática ambiental como é caso dos artigos 5, LXXIII, artigo 23, III, VI; artigo 24, VI, VIII, artigo 129, IIII; artigo 170 e 225.

Diante de um cenário no qual a atual carga tributária beira a insuportabilidade, e o modelo de atuação estatal, por meio da cobrança de tributos, demonstra que não obteve êxito, a proposta de extrafiscalidade pautada na redução da carga tributária, pode ser vista de forma mais simpática pelos contribuintes, que num primeiro momento, perceberão somente os ganhos diretos de tal política, mas que de forma indireta contribuirão com a adoção de alguma medida de proteção ao meio ambiente.

Não se trata, pois, de uma inovação sem precedentes, visto que, a extrafiscalidade já vem sendo utilizada há muito tempo, com vistas à realização dos direitos fundamentais no contexto brasileiro. Basta lembrar o caso do Imposto sobre Produtos Industrializados, utilizado no sentido de estimular determinados setores da economia ou do Imposto Territorial Rural - ITR, visando o cumprimento da função social da propriedade. ${ }^{15}$

15 No sistema tributário brasileiro, o imposto extrafiscal por excelência - e o que mais relações apresenta com a solidariedade social - é o imposto territorial rural de competência federal. 
O que se pretende é a ampliação do uso da tributação como meio direcionador de comportamentos voltados para práticas ambientalmente corretas e, a adoção de políticas preventivas voltadas para diminuição do risco ambiental.

Desta forma, constata-se que a extrafiscalidade tem um importante papel a desempenhar em um cenário que vise a concretização do direito fundamental ao meio ambiente ecologicamente equilibrado. Direito este que se encontra, como visto, intimamente ligado ao direito à vida.

É certo que a indução ou desestímulo de comportamentos pode se dar mediante a adoção, de um lado, de normas sancionadoras de condutas ilícitas e, de outro, com a majoração ou diminuição de tributos a partir da adoção de determinados comportamentos. Como menciona Souza, o direito, com o objetivo de alterar comportamentos humanos e, por consequência, alcançar determinados interesses sociais, poderá agir de duas formas:

a) por intermédio de normas que estabeleçam sanções civis, administrativas ou penais para os atos que repudia; ${ }^{16}$

b) da gradação de tributos como forma de desestímulo ou incentivo às condutas desejadas, situação em que se verifica o caráter extrafiscal da exigência. ${ }^{17}$

Vale frisar, na linha do exposto pelo autor acima citado, que a extrafiscalidade ambiental não se confunde com a imposição de sanções pecuniárias em face da prática de ilícitos causadores de danos ambientais. Ou seja, os ditos tributos ambientais não correspondem a sanções pela prática de ato ilícito, mesmo

A Constituição Federal de 1988 não poderia ter sido mais explícita quanto à profundas ligações desse imposto com a ideia de solidariedade social, e quanto as providências que deveriam tomar os Poderes Públicos para fazer valer tais ligações: "o imposto previsto no inciso VI (ITR) terá suas alíquotas fixadas de forma a desestimular a manutenção de propriedades improdutivas e não incidirá sobre pequenas glebas rurais, definidas em lei, quando as explore, só ou com sua família, o proprietário que não possua outro imóvel". (art. 153, § $4^{\circ}$ da CF em sua redação original). GODOI, Marciano Seabra de; GRECO, Marco Aurélio. Tributo e solidariedade social. Solidariedade Social e Tributação. SP: Dialética, 2005, p. 163

16 Segundo o disposto no $\S 3^{\circ}$, do artigo 225, da CF/88, "as condutas e atividades consideradas lesivas ao meio ambiente sujeitarão os infratores, pessoas físicas ou jurídicas, a sanções penais e administrativas, independentemente da obrigação de reparar os danos causados".

17 SOUZA, Jorge Henrique de Oliveira Souza. Op. cit., p. 101 
porque, conforme dispõe o art. $3^{\circ}$ do Código Tributário Nacional, os tributos apenas podem incidir em relação às atividades lícitas, sendo que no caso da extrafiscalidade ocorre um estímulo ou desestímulo tendo como norte orientar comportamentos ambientalmente adequados.

A título de exemplo, abaixo serão apresentados alguns impostos que já são ou foram utilizados com o caráter da extrafiscalidade e que podem gerar ou desestimular algum comportamento ambiental:

a) Imposto sobre Produtos Industrializados (IPI): O Decreto Federal 755/1993 impôs alíquotas diferenciadas sobre os veículos movidos à álcool (20 ou 25\%), e para veículos a gasolina (25 ou 30\%), estimulando o uso do combustível obtido mediante de fontes renováveis;

b) Imposto Territorial Rural: A Lei Federal 9.393/1996 estabeleceu a modalidade de extrafiscalidade ambiental para desestimular a manutenção das propriedades improdutivas, graduando progressivamente as alíquotas de ITR.

c) Imposto de Renda: a Lei Federal 5.106 de 1996 dispõe sobre os incentivos fiscais concedidos a empreendimentos florestais, ou seja, autoriza a dedução do IR da pessoa física e jurídica de despesas realizadas com reflorestamento;

d) Imposto sobre Importação: o art. 153, $\$ 1^{\circ}$, da CF/1988 atribui ao Poder Executivo a prerrogativa de aumentar a alíquota deste imposto quando ocorrer a importação de produtos potencialmente nocivos ao meio ambiente, ou, do contrário, diminuir tal alíquota, para estimular a importação de produtos que contribuam com a preservação ambiental.

e) Imposto sobre Produtos Industrializados: como forma de estimular a economia em face à Crise Financeira de 2008, foi reduzida a alíquota de IPI em relação à eletrodomésticos (linha branca), condicionado-se tal redução a existência do Selo Verde, concedido pelo IMETRO aqueles eletrodomésticos com baixo consumo de energia.

Numa linha paralela - mas não coincidente - alguns estados brasileiros ( $P R, S P$, MT, PE e RJ, dentre outros) implantaram o denominado "ICMS ecológico", o que implica a adoção de critérios ambientalmente relevantes para o repasse de parte 
da arrecadação que cabe aos municípios, beneficiando aqueles que promovem a proteção ambiental. ${ }^{18}$ Neste caso, há de se reconhecer que não se está diante de uma extrafiscalidade típica, pois apenas ocorre uma repartição das receitas a partir de critérios ecológicos.

Uma vez pensada a tributação a partir da concretização dos direitos fundamentais, não parece difícil encontrar os meios com os quais poderá se garantir que, indiretamente, seu formato privilegie o direito fundamental ao meio ambiente ecologicamente equilibrado. É certo que a tributação ambiental não resolverá todos os problemas existentes, pois esta também se encontra limitada pelos preceitos constitucionais.

Por isso, a tributação deve ser considerada como mais um meio de se alcançar os objetivos constitucionais e não como um instrumento isolado. A partir disso, questiona-se: de que outras formas pode a tributação servir de instrumento de concretização desse direito, via extrafiscalidade? A resposta a este questionamento não conseguirá esgotar as possibilidades de uso da ferramenta, mas poderá conduzir ao estabelecimento de parâmetros mínimos que devem orientar o uso desta.

O primeiro parâmetro a ser estabelecido para o uso de políticas extrafiscais de caráter ambiental é no sentido de se utilizar as mesmas para estimular comportamentos ambientalmente corretos, ou seja, estimular políticas preventivas que evitem o risco ambiental, ou ainda, que desestimulem a poluição e a degradação ambiental. ${ }^{19}$

Desta forma, supera-se o entendimento de que a defesa do meio ambiente deve ficar adstrita às sanções ou reparações ambientais. A intenção de se desestimular 18 No Rio de Janeiro, desde 2007, o ICMS contempla municípios cariocas que alcançam determinadas metas ambientais como a ampliação do sistema de esgoto, melhoria na coleta e destinação de resíduos, ampliação e conservação de áreas verdes, entre outros. A partir do exercício fiscal de 2011, a participação do componente ambiental no cálculo do repasse do ICMS aos municípios subiu de $1,8 \%$ para $2,5 \%$, como previsto no decreto. FREITAS, Ghedes de. Estado distribui mais de R\$100 milhões de ICM Verde. Disponível em http://www.rj.gov. br/web/imprensa/ exibeconteudo?article-id=376224, acesso em 29 de março de 2011.

19 Casalta Nabais reforça a importância desta busca quando afirma que no respeitante ao suporte financeiro da ação do estado em matéria de proteção do ambiente, já quem defenda e proponha a instituição de tributos ou taxas ambientais que, para além de constituírem um suporte financeiro da ação do estado nessa área, teriam também por objetivo a orientação dos comportamentos dos indivíduos e das empresas no sentido da defesa ambiental. CASALTA NABAIS, José. Estudos de Direito Fiscal: por um estado fiscal suportável. Coimbra: Almedina, 2005, p. 50 
um determinado comportamento ambiental é no sentido de convencer o empresário de que a utilização de uma matéria-prima menos poluente pode, além de ser ambientalmente correta, ser economicamente mais vantajosa. Do contrário, o estímulo aos comportamentos ambientais poderia conduzir ao consumo de produtos "ecologicamente corretos" ou "ambientalmente sustentáveis".

A utilização de impostos ou contribuições sociais (com características de impostos afetados), para assegurar o direito ao meio ambiente ecologicamente equilibrado é possível por meio do mecanismo da seletividade, ou seja, a denominada tributação ambiental, via extrafiscalidade, pode ser implementada mediante a fixação de alíquotas seletivas, conforme o grau de adequação da atividade, produtos ou serviços com o objetivo constitucional de assegurar a todos um meio ambiente ecologicamente equilibrado. ${ }^{20}$

Por meio da extrafiscalidade pode-se ainda desonerar por completo a incidência tributária, quando for demonstrado que os produtos e os serviços são compatíveis com o objetivo da preservação do meio ambiente.

A ampliação da utilização da extrafiscalidade ambiental implica rompimento com a desgastada fórmula de se arrecadar recursos para, exclusivamente com estes, buscar a concretização de direitos fundamentais. É certo que esse rompimento não é total, mas mediante a indução de comportamentos o Estado tem potencialmente a possibilidade de dar a máxima eficácia ao direito fundamental ao meio ambiente equilibrado, o que reconhecidamente não é possível fazer apenas com a existência de recursos financeiros disponíveis.

Por tudo isso, também fica claro que não há necessidade de se criar novos impostos ou taxas com caráter ambiental. Deve-se, sim, introduzir e ampliar a conotação extrafiscal nos tributos existentes.

Mas é somente no sentido de desoneração que o instituto da extrafiscalidade pode ser utilizado. Algumas das hipóteses possíveis, da sua aplicação com o sentido de oneração da atividade são apresentadas a seguir. 20 BUFFON, Marciano. Op. cit., p. 250 
No caso do Imposto de Importação, quando da importação de produtos compreendidos como nocivos ao meio ambiente, pode o Poder Executivo, com base no $\S 1^{\circ}$ do art. 153 da CF/88, majorar a alíquota deste imposto, com o objetivo de desestimular tal importação. Este seria o caso, antes da total proibição, da importação de pneus usados realizada por anos no Brasil.

No que se refere ao Imposto Territorial Rural (ITR), pode-se estimular a proteção ambiental nas propriedades rurais, posto que as disposições constitucionais acerca deste imposto permitem que suas alíquotas sejam fixadas de forma a desestimular a manutenção de propriedades improdutivas. A proteção ambiental pode auxiliar no cumprimento deste objetivo, ou seja, permitir que a propriedade não seja classificada como improdutiva. Exemplo disto são as RPPNs (Reserva Particular do Patrimônio Natural) instituídas pelo Decreto N. 5.746, de 05 de abril de 2006. Uma vez identificadas na propriedade áreas passíveis de averbação na condição de RPPN, pode o proprietário requerer o mesmo ao IBAMA, que homologando o pedido instituirá sobre a propriedade uma Unidade de Conservação Particular. Segundo a Lei 9.393, de 1996, a área criada como RPPN é excluída da área tributável do imóvel para fins de cálculo do ITR.

Acerca do Imposto sobre a Propriedade de Veículos Automotores (IPVA), as alíquotas de tal imposto poderiam ser diferenciadas segundo a função e a utilização dos veículos, tendo como parâmetro a diminuição da emissão de gases poluentes. A utilização de combustíveis ecologicamente corretos, ou mais corretos, como é o caso do álcool, poderiam ser estimulados mediante a desoneração da incidência do IPVA. De outra banda, veículos que utilizam combustíveis fósseis mais poluentes poderiam vir a pagar alíquotas maiores.

Como último exemplo pode-se citar o caso do Imposto Predial e Territorial Urbano (IPTU) de competência dos municípios. O IPTU pode ser o responsável pelo estímulo à manutenção de vegetação em imóveis urbanos, ou ainda, pela adoção de práticas ambientalmente adequadas de construção.

O município poderia, por exemplo, aplicar alíquotas menores, para os proprietários que mantivessem um percentual previamente estabelecido de vegetação sobre o imóvel ou, ainda, para os proprietários que viessem a 
adotar práticas ecologicamente corretas, como a coleta da água da chuva para determinados usos, a captação de energia solar, entre outros.

Além disso, uma desoneração parcial do IPTU poderia estar condicionada à destinação do lixo orgânico doméstico, mediante a implantação na residência dos contribuintes de tal imposto do método da "compostagem", segundo o qual - singelamente - o lixo orgânico é armazenado até transformar-se em adubo, que pode ser utilizado na produção de hortaliças e frutas.

Enfim, cabe referir que assim como em relação a outros direitos fundamentais é mister que a escolha sobre como a tributação pode contribuir para concretização do direito ao meio ambiente deve se dar de forma democrática, para que esta se torne legítima e realmente atinja seus fins.

\section{CONSIDERAÇÕES FINAIS}

Haverá um momento, no futuro, em que os pósteros olharão para os seus antepassados e farão uma espécie de julgamento histórico sobre o que esta geração fez com os dias que lhes foram dados a existir. Quando este momento chegar, os que hoje coexistem têm o dever de garantir que os seus filhos e netos possam sentir orgulho do que foi feito ao seu tempo. Esse é um compromisso histórico que a sociedade atual tem: o compromisso moral de legar aos que estão por vir um mundo menos injusto, mais humanizado e preservado.

Contudo, tal não ocorrerá se o processo de degradação ambiental continuar a sua inexorável marcha, se - em nome do interesse econômico - a devastação e a destruição da flora e da fauna ocuparem um espaço central no noticiário. Ademais, não ocorrerá se a questão ambiental, hipocritamente, permanecer como um instrumento de "marketing" de tantos ou um assunto sobre o qual poucos ousam declararem-se contrários, ainda que adotem práticas diametralmente opostas. Aliás, nesse ponto, se os comerciais veiculados na mídia, tendo a "causa ambiental" como razão de ser, resultassem em práticas ecologicamente adequadas, provavelmente, trabalhos como este sequer seriam necessários. O que se percebe, pois, é que até esta nobre causa tornou-se um pretexto para a maximização do interesse econômico. 
Vive-se, por conseguinte, num momento decisivo para o futuro desta e das próximas gerações. Poucas vezes, as opções e os caminhos adotados tiveram tanto impacto no tempo que sucederá. Em poucos momentos da história, o risco da inviabilidade esteve tão próximo e tão perceptível, exceto para aqueles que se recusam a percebê-lo em prol de seus individuais interesses.

Sendo assim, há de se reconhecer que o status de direito fundamental do direito ao meio ambiente ecologicamente equilibrado vincula e compromete todos os Poderes e evidentemente toda a sociedade. Esta vinculação impõe ao Estado a busca de mecanismos e instrumentos eficazes à realização de tão significativa tarefa.

Nesse contexto, a extrafiscalidade ambiental apresenta-se como uma ferramenta inequivocamente útil, uma vez que pode ser utilizada para estimular comportamentos preventivos, levando-se em consideração também o conceito de risco ambiental, ou ainda para desestimular práticas contrárias ao meio ambiente. No entanto, a face mais eficaz da extrafiscalidade ambiental diz respeito à concessão de benefícios fiscais.

De qualquer sorte, é necessário ter sempre presente que a concessão dos benefícios ou das isenções fiscais deve observar processos democráticos de discussão e aprovação, sob pena destes também se transformarem em mecanismos de favorecimento de poucos ou de distribuição de privilégios.

Com este trabalho, pretendeu-se defender que a tributação passe a existir em razão do ser humano e não do interesse econômico de alguns - também seres humanos -, embora desprovidos de sentimento de solidariedade com seus pares e pósteros. Para tanto, impõe-se a adoção do interesse ecológico, de tal forma que a exigência fiscal esteja intimamente compromissada com a grande promessa feita pela revolucionária Carta Brasileira de 1988.

Esta vinculação impõe ao Estado a busca por mecanismos e instrumentos eficazes para realização deste direito, e é neste viés que se pode utilizar a extrafiscalidade, sendo que seus contornos conceituais não podem ficar à mercê de políticas midiáticas oportunistas, fazendo-se da Carta vinculante uma mera obra de ficção.

O objetivo da extrafiscalidade pode ser tanto no sentido de estimular como desestimular determinados comportamentos, visando sempre ao bem comum 
e, por consequência, o direito ao meio ambiente, ficando claro assim o caráter interventivo do Estado. Apesar de permitir o ingresso de recursos para os cofres públicos, não é este seu maior objetivo.

No âmbito ambiental a extrafiscalidade pode ser utilizada para estimular comportamentos preventivos que trabalhem com o conceito de risco ambiental, ou ainda, para desestimular práticas contrárias ao meio ambiente, isto porque, ao estabelecer algumas hipóteses de extrafiscalidade, a constituição não exclui a possibilidade de se utilizar a exigência tributária para outros fins instituídos constitucionalmente como o meio ambiente.

O objetivo que mais se vincula à proposta apresentada no pressente artigo é o do uso da extrafiscalidade por meio da concessão de benefícios fiscais, haja vista que tal emprego mostra-se mais eficaz na concretização do objetivo perseguido. Outrossim, há o entendimento de que a carga tributária brasileira não permite mais a majoração ou a instituição de novas contribuições.

Apresentando-se como a melhor proposta, é necessário fazer um alerta no sentido de que a concessão dos benefícios ou das isenções fiscais deve observar processos democráticos de discussão e aprovação, sob pena desta também se transformar em um mecanismo de favorecimento de poucos ou de distribuição de privilégios. Só terá legitimidade o benefício fiscal que for orientado pelos objetivos constitucionais e pelos limites impostos à tributação.

Enfim, há de se garantir, a todo custo e com toda energia possível, que a existência nesse privilegiado espaço do planeta possa restar assegurada dignamente a todos, em um ambiente que permita com que as mais diversas manifestações de vida sejam harmonicamente viáveis e possíveis. Este é o tempo em que se vive e o que for feito nele dependerá a vida dos que estão por vir. Está posto o grande desafio!

\section{REFERÊNCIAS DAS FONTES CITADAS}

BONAVIDES, Paulo. Curso de Direito Constitucional. 12. ed. SP: Malheiros, 2002

BUFFON, Marciano. Tributação e dignidade humana: entre os direitos e deveres fundamentais. Porto Alegre: Livraria do Advogado, 2009. 
Tributação no Brasil do Século XXI: uma abordagem hermeneuticamente crítica. Porto Alegre: Livraria do Advogado, 2015.

CASALTA NABAIS, José. Estudos de Direito Fiscal: por um estado fiscal suportável. Coimbra: Almedina, 2005

O Dever Fundamental de Pagar Impostos. Coimbra: Almedina. 2004.

FREITAS, Ghedes de. Estado distribui mais de R $\$ 100$ milhões de ICM Verde. Disponível em http://www.rj.gov.br/web/imprensa/exibeconteudo?article-id=376224, acesso em 29 de março de 2011.

GODOI, Marciano Seabra de; GRECO, Marco Aurélio. Tributo e solidariedade social. Solidariedade Social e Tributação. SP: Dialética, 2005

LEITE, José Rubens Morato; CANOTILHO, José Joaquim Gomes. Direito Constitucional Ambiental Brasileiro. São Paulo: Saraiva, 2007

MARCHESAN, Ana Maria Moreira; STEIGLEDER, Annelise Monteiro; CAPPELI, Sílvia. Direito Ambiental. 6 ed. Porto Alegre: Verbo Jurídico, 2010

MILARÉ, Édis, Direito do Ambiente. São Paulo: RT, 2000

SOUZA, Jorge Henrique de Oliveira. Tributação e Meio Ambiente. Belo Horizonte: Del Rey, 2009

Recebido em: mai/2016

Aprovado em: ago/2016 